\title{
Multimethodological Approach to Gastrointestinal Microsporidiosis in HIV-Infected Patients
}

\author{
Jorge Néstor Velásquez ${ }^{1}$. Cecilia di Risio ${ }^{2} \cdot$ Cristina Etchart $^{2} \cdot$ Agustín Víctor Chertcoff $^{3}$. Osvaldo Germán Astudillo ${ }^{3}$. \\ Silvana Carnevale ${ }^{3,4}$
}

Received: 24 January 2019 / Accepted: 14 June 2019

(c) Witold Stefański Institute of Parasitology, Polish Academy of Sciences 2019

\begin{abstract}
Purpose Microsporidiosis is an opportunistic infection that produces chronic diarrhoea and cholangiopathy in patients with AIDS, mainly caused by two species of microsporidia, Enterocytozoon bieneusi and Encephalitozon intestinalis. The aim of this work was to develop an integral system for the diagnosis of microsporidiosis of the intestine and biliary tract in HIVinfected patients, comprising microscopic and molecular techniques.

Methods The study population comprised 143 adult patients of both sexes with diagnosis of HIV infection, with chronic diarrhoea, and with or without HIV-associated cholangiopathy. Stool studies for microsporidia identification of spores were performed on each patient. A video esofagogastroduodenoscopy with biopsy collection was also carried out for routine histology and semi-thin sections stained with Azure II. Species identification was carried out by transmission electron microscopy and/or polymerase chain reaction for the species E. bieneusi and E. intestinalis.

Results Out of the 143 patients a total of $12.6 \%(n=18)$ were infected with microsporidia. Microsporidia species identified in most cases was E. bieneusi (16/18 cases), followed by E. intestinalis (4/18), all of these last ones in coinfection with $E$. bieneusi.

Conclusions Clinical, imaging, microscopic and molecular analyses, when applied in a systematic and integrated approach, allow diagnosis and identification of microsporidia at species level in AIDS patients with chronic diarrhoea, and with or without HIV-associated cholangiopathy.
\end{abstract}

Keywords Microsporidiosis $\cdot$ Enterocytozoon bieneusi $\cdot$ Encephalitozoon intestinalis $\cdot \mathrm{HIV}$

\section{Introduction}

Microsporidia are obligate intracellular eukaryotic organisms which lack mitochondria, with non-typical Golgi apparatus and peroxisomes and ribosomes resembling those of

Jorge Néstor Velásquez

jorgeysilvana@speedy.com.ar

1 Hospital Municipal de Infecciosas "Dr. Francisco Javier Muñiz”, Uspallata 2272, CP 1282, Buenos Aires, Argentina

2 Hospital Municipal General de Agudos "Dr. José María Penna”, Pedro Chutro 3380, CP 1437, Buenos Aires, Argentina

3 Instituto Nacional de Enfermedades Infecciosas, ANLIS "Dr. Carlos G. Malbrán”, Avenida Vélez Sársfield 563, CP 1281, Buenos Aires, Argentina

4 Consejo Nacional de Investigaciones Científicas y Técnicas (CONICET), Buenos Aires, Argentina bacteria $[18,19,30,53,88]$. This phylum consists of more than 1200 species that infect a wide range of vertebrates and invertebrates $[16,109]$. To date there are ten genera of microsporidia that have been identified as causing human infections including Encephalitozoon, Enterocytozoon, Trachipleistophora, Pleistophora, Anncalia, Nosema, Vittaforma, Tubulinosema, Microsporidium and Endoreticulatus $[26,43,78,102]$.

Microsporidia have been recognized as infectious agents worldwide, with reported cases in developed and developing countries [6, 14, 15, 37, 39, 48, 50, 51, 70, 95]. In Argentina the characteristics of the disease are unknown in terms of prevalence, morbidity and mortality.

Standard diagnostic methods depend on the detection of the organisms in fluids, stool and biopsy specimens by light or electron microscopy [104, 105]. Light microscopy presents a challenge due to the small size of the organisms (about 3 um), with a detection limit of 103-104 spores/ 
gram of stool [83]. Meanwhile, electron microscopy is the definitive procedure for the identification of species, but requires expensive and specialized equipment and has low sensitivity. The identification of species of microsporidia is clinically useful because of the existence of differences in the response to the therapy and depends on the ultrastructural and/or molecular analysis. Molecular techniques that have been developed for the diagnosis of human microsporidiosis correspond to PCR, restriction fragment length polymorphism (RFLP), Southern blot analysis, single-strand conformational polymorphism (SSCP), in situ hybridization, DNA sequencing, real-time PCR, Luminex, loop-mediated isothermal amplification (LAMP) and multiplex commercial kit $[20,21,29,32-34,42,44,45,61$, 62, 67, 69, 71-73, 91, 92, 96, 97, 99, 110].

Enterocytozoon bieneusi and E. intestinalis are the most common species infecting the gastrointestinal tract. In AIDS patients E. bieneusi has been identified in different tissues such as intestinal epithelium, lamina propria, bile duct, pancreatic, bronchial and nasal epithelium. $E$. intestinalis has been identified in the intestinal epithelium and lamina propria, endothelial, renal tubule cells, biliary tract, nasal and bronchial epithelium and other tissues [43, 104]. Co-infection of more than one species of microsporidia can be found in this group of patients [9]. Patients with AIDS and microsporidiosis have a variety of clinical manifestations ranging from asymptomatic to severe medical conditions that depend on the location of the infection and CD4 cell count [56-58]. The clinical presentations in this group of patients include asymptomatic, symptomatic intestinal and symptomatic extraintestinal. Asymptomatic clinical forms have a prevalence of about $2-11 \%$ [2, 86] and are associated with high CD4 cell count. In the intestinal symptomatic forms, patients with a CD4 count greater than 200 cells $/ \mathrm{mm}^{3}$ present acute or persistent diarrhoea [81]. With CD4 counts higher than 200 cells $/ \mathrm{mm}^{3}$, acute and chronic diarrhoea may evolve towards healing [81]. Patients with CD4 counts between 100 and 200 cells/ $\mathrm{mm}^{3}$ present chronic diarrhoea. The CD4 counts lower than 100 cells $/ \mathrm{mm}^{3}$ are associated with symptoms of diarrhoea that can persist for years and lead to extraintestinal sites producing cholangiopathy and pancreatitis $[43,105]$. Watery diarrhoea, dehydration, hypovolemia and death are associated with a CD4 count lower than 100 cells $/ \mathrm{mm}^{3}$ $[13,37,52]$. Intestinal perforation has been described in a patient infected with E. intestinalis. The infection of the biliary tract is one of the most frequent extraintestinal clinical manifestations and has been described in $10 \%$ of patients with AIDS and intestinal microsporidiosis without antiretroviral therapy [59]. The species E. bieneusi causes alithiasic cholecystitis, pancreatitis and sclerosing cholangitis [80]. The species E. intestinalis causes acalculous cholecystitis, sclerosing cholangitis, pancreatitis and disseminated infection $[17,108]$. The level of CD4 cells in this group of patients is generally lower than 100 cells/ $\mathrm{mm}^{3}$ [80].

Before the use of antiretroviral therapies, microsporidiosis had been reported in at least $15 \%$ (and up to $85 \%$ ) of HIV/AIDS patients [89]. Since the advent of antiretroviral therapy (ART) and its progressive introduction starting in 1996, opportunistic infections such as microsporidiosis have substantially decreased in developed countries [40] due to the reconstitution of the immune system of the patients. This contrasts with the situation in developing countries, with limited or no access to ART, where opportunistic infections, including those due to microsporidia, remain problematic [38, 87, 94]. A recent review and meta-analysis [101] showed that the global prevalence of microsporidia infection in HIV-infected people ranged between 0.7 and $81.3 \%$. The estimated pooled prevalence was $11.8 \%$ overall, significantly higher in low-income countries than in middle-income countries. The infection rates of the species E. bieneusi in HIVinfected patients are usually in the range of $1.3-11.6 \%$, with higher rates reported in Nigeria, Iran, and Australia [60].

The aim of this work was to develop an integral system for the diagnosis of microsporidiosis of the intestine and biliary tract in HIV-infected patients, comprising microscopic and molecular techniques in fluid and biopsy specimens.

\section{Materials and Methods}

\section{Studied Population and Sample Collection}

The studied population comprised 143 adult patients, with ages in the range of 20 and 50 years, corresponding to 120 males and 23 females, diagnosed with HIV who attended Hospitals Francisco J. Muñiz and José María Penna, Buenos Aires city, Argentina, complaining of chronic diarrhoea (considered when lasting a month or longer) with or without HIV-associated cholangiopathy and CD4 counts less than 500 cells $/ \mathrm{mm}^{3}$. Stool samples and duodenal biopsies were studied. Samples were collected since 2012 until 2018.

$\mathrm{HIV}$-associated cholangiopathy was confirmed by endoscopic retrograde cholangiopancreatography (ERCP) and/or magnetic cholangioresonance (CR) of liver and biliary tract. A group of 11 patients who met the inclusion criteria were selected among the 143 studied patients.

The research protocol was approved by the Ethical Committee for Research, Hospital Francisco J. Muñiz, protocol no. 274.

The stool samples were collected during 7 days in 5\% formalin saline solution and stored at room temperature until processed.

An upper gastrointestinal endoscopy (UGE) was performed to each patient with a Pentax EPM 2000 equipment. 
Endoscopic images of the duodenal mucosa were classified ([63], with modifications) as normal duodenum, granular duodenum when the mucosa presented congestive base with a thin whitish nodularity, jasper duodenum when the folds were flattened with congestive patches, and atrophic duodenum when the folds were deleted and visible vessels were seen by transparency. Five or more biopsy specimens from the distal duodenum were obtained in all cases showing or not macroscopic lesions, and they were stored in $10 \%$ formalin, Karnovsky's fixative and at $-20{ }^{\circ} \mathrm{C}$ in saline solution. In cases with cholangiopathy, peripapillary duodenum samples were obtained.

An ERCP and/or CR were performed in patients with clinical manifestations, humoral pattern of cholangiopathy and bile duct abnormalities by ultrasonography suggestive of cholangiopathy. For the patients who underwent ERCP, a papilla biopsy was obtained and fixed in formalin $10 \%$ and Karnovsky fixative. ERCP was performed with an Olympus TJF 100 videoduodenoscope. The bile duct was cannulised and ERCP was performed with contrast medium at low pressure. The site, extension and radiological characteristics of the lesion were determined. The bile duct abnormalities in ERCP and/or CR were classified [22] as papillary stenosis (PS), sclerosing cholangitis (SC), association of the two previous abnormalities and long common bile duct stenosis.

\section{Microscopy Analysis}

Faeces samples were concentrated by ethyl ether centrifugation [93]. Thin smears were prepared from the pellets and observed by light microscopy at a magnification of 1000 after modified trichrome [103] and Gram-chromothrope [68] stains.

Formalin-fixed samples were embedded in paraffin and sliced in 5-10 $\mu \mathrm{m}$ sections. They were stained with hematoxylin and eosin (H\&E) and Giemsa for light microscopy observation. In cases where compatible structures with microsporidia were observed, a methenamine silver staining [5] was performed. Samples in Karnovsky's fixative were dehydrated and embedded in polybedaraldita. Semi-thin sections of $1 \mu \mathrm{m}$ thickness were sliced and stained with Azure II for observation by light microscopy.

The diagnosis of microsporidiosis was carried out by the identification of spores and structures of the merogony and sporogony stages by light microscopy.

In cases that met diagnostic criteria for microsporidiosis, the degree of inflammation and atrophy was determined following the concepts of different authors with modifications tailored to our work [36, 84]. We evaluated well-targeted 5-10 villi where the following characteristics were analysed: mucosal appearance, that may have different morphologies such as a mixed villi pattern (villi have a finger and/ or foliaceus and/or ridges-like appearance), cerebriform, convolution, branching or mosaic with flattened mucosa; the villus:crypt ratio, considering a normal ratio of $3: 1$; description of epithelial infiltrates, including the number of intraepithelial lymphocytes (lower or higher than 30 lymphocytes per 100 epithelial cells), the presence or absence of polymorphonuclear cells or eosinophils; description of infiltrates in the lamina propria, with cell type in the three rows below the villi (considering normal $60 \%$ plasmocytes with a lymphocytes, eosinophils and histiocytes remaining). Crypt hyperplasia was considered when an elongation of the same size was observed.

In cases where compatible structures with microsporidia were detected by light microscopy, the samples were processed for TEM as previously described [12] and examined using a Carl Zeiss EM-109 equipment.

\section{Molecular Diagnosis}

Molecular techniques were carried out in those cases with diagnostic criteria of microsporidiosis in stool samples (spores) and/or biopsy specimens (spores, meronts, sporonts).

DNA purification was performed according to previous protocols [96], by standard phenol-chloroform extraction and ethanol precipitation. For biopsy specimens, an initial tripsinization step was added.

A PCR protocol for E. bieneusi was applied as previously described [96] for the amplification of a 210-bp fragment corresponding to the internal transcribed spacer (ITS) of the rRNA genes with the primers set Eb.gc::Eb.gt.

The PCR reaction for E. intestinalis was carried out [31] for the amplification of a 520-bp region of the SS rDNA employing the primers set SINTF1::SINTR, with modifications as previously described [98].

Samples resulting negative for $E$. bieneusi and $E$. intestinalis were analysed by PCR employing the universal primers set 18f::1492r [106] that amplifies most of the small subunit rRNA of the microsporidia.

Amplification products were analysed electrophoresis in $2 \%$ agarose gel stained with ethidium bromide.

\section{Results}

\section{Prevalence and Pathogenicity}

Microorganisms were identified in stool and/or biopsy specimens in 63 cases.

Etiologic agents were: Crytosporidium sp. $(n=22)$, microsporidia $(n=18)$, Cystoisospora belli $(n=14)$, Cytomegalovirus $(n=12)$, Giardia duodenalis $(n=7)$, Strongyloides stercoralis $(n=4)$, Mycobacterium tuberculosis $(n=2)$, Histoplasma capsulatum $(n=2)$, Mycobacterium avium intracellularis $(n=2)$, Cryptococus neoformans 
$(n=1)$ and Cyclospora cayetanensis $(n=1)$. Coinfections were detected in 12 cases.

The diagnosis of microsporidia was positive in 18 out of the 143 cases (12.6\%). The species in most cases was $E$. bieneusi (16/18 cases) followed by E. intestinalis (4/18). All cases with $E$. intestinalis were coinfected with $E$. bieneusi. Out of the 18 cases of microsporidiosis, 4 presented cholangiopathy and they were identified as E. bieneusi.

Microsporidia-infected patients were aged 23-51 years; 15 were males and 3 females. Sexual behaviour corresponds to 13 heterosexual and 5 homosexual. Two patients were intravenous drug abusers. Diarrhoea duration was 3-12 months. Most cases had a number of depositions higher than 10 per day (12/18), incontinence (11/18), weight loss (15/18) and vomiting (10/18). Some patients also presented dysphagia (2/18), abdominal pain (2/18), right upper quadrant abdominal pain (4/18) and pancreatitis (1/18).

In patients not receiving antiretroviral therapy $(11 / 18$ cases) CD 4 count was less than 100 cells $/ \mathrm{mm}^{3}$ in 8 cases, between 100 and 200 cells $/ \mathrm{mm}^{3}$ in two cases and in one case more than $200 / \mathrm{mm}^{3}$. In patients receiving antiretroviral therapy ( $7 / 18$ cases) CD4 count was less than 100 cells $/ \mathrm{mm}^{3}$ in 1 case, between 100 and 200 cells $/ \mathrm{mm}^{3}$ in 5 cases and higher than 200 cells $/ \mathrm{mm}^{3}$ in only one case. The endoscopic appearance of the duodenal mucosa presented a granular appearance in 9/18 cases, jasper in 3/18 cases and normal in $6 / 18$ cases. Table 1 summarizes the most significant clinical and microbiological characteristics associated with each of the patients with microsporidosis. Evolution of each patient is described in Table 2.

\section{Diagnosis by Light Microscopy}

Concentrated formalin-preserved faeces were stained with modified trichrome and Gram-chromotrope and observed by light microscopy (Fig. 1a, b), allowing the identification of spores in 13 of 143 cases (9\%).

Duodenal biopsy specimens stained with Giemsa, H\&E, methenamine silver and Azure II allowed the identification of structures compatible with microsporidia by light microscopy (Figs. 2a-c, 3a, b) in 18 of 143 cases (12.6\%). Giemsa, $\mathrm{H} \& \mathrm{E}$ and methenamine silver stains identified structures in 16 of 18 cases and Azure II in all cases.

\section{Degree of Inflammation and Atrophy}

In all cases that met diagnostic criteria for microsporidiosis the degree of inflammation and atrophy was determined. Most patients presented an aspect of the mucosa with a mixed villi pattern (17/18) with a villus:crypt ratio of $2: 1$ (17/18). In four cases more than 30 lymphocytes per 100 epithelial cells were found. The lamina propria presented infiltrates with mononuclear predominance in most cases
(15/18). In all patients crypt hyperplasia was observed. Among the 10 cases where the identified species was $E$. bieneusi without other microorganisms, in 6 cases there was an increased number of intraepithelial lymphocytes.

\section{Diagnosis by Transmission Electron Microscopy}

Transmission electron microscopy was performed in four patients with microsporidiosis. The species E. bieneusi was identified in the 4 cases, one of them in coinfection with $E$. intestinalis (Figs. 2d, 3c).

\section{Molecular Diagnosis}

The PCR technique for the identification of the species $E$. bieneusi and $E$. intestinalis in faecal samples and/or biopsies was used in all patients diagnosed with microsporidiosis $[31,96]$. Faecal samples were analysed in $11 / 18$ cases and biopsies in $18 / 18$ cases. The species $E$. bieneusi was identified in 16 patients. In 4 of the 16 patients a coinfection with the species E. intestinalis was identified (Table 1). In two patients with spores in stool and structures compatible with microsporidia in duodenal biopsies species $E$. bieneusi and $E$. intestinalis were not identified, but this sample resulted positive employing the universal primers.

\section{Discussion}

More than 100 million people are infected with HIV worldwide. Diarrhoea in patients with HIV may affect $50 \%$ of cases in the United States and an even higher percentage in developing countries, reaching $80 \%$ with or without antiretroviral therapy [23, 101]. HIV-associated cholangiopathy affected $30 \%$ of AIDS patients in the pre-ART era [24]. However, although fewer cases are described due to antiretroviral therapy, they continue appearing [35]. The species of microsporidia E. bieneusi and E. intestinalis are cause of diarrhoea and HIV-associated cholangiopathy.

With the methodology described here microorganisms were identified in 63/143 cases reaching approximately $44 \%$, in concordance with previous studies [27,54]. The most common organisms identified in our study were Cryptosporidium spp., microsporidia, Cystoisospora belli, Cytomegalovirus and Giardia duodenalis. Cryptosporidium spp. and microsporidia have been the most common causes of chronic diarrhoea in HIV-infected in the pre-ART era in numerous series of works $[9,47,107]$. With the use of ART opportunistic infections with Cryptosporidium sp. and microsporidia decreased their prevalence [28, 55, 66]. Many authors agree that diagnosis of microsporidia should be present even with the use of ART in patients with chronic diarrhoea, weight loss and a CD4 cell count of about 100 cells/ 


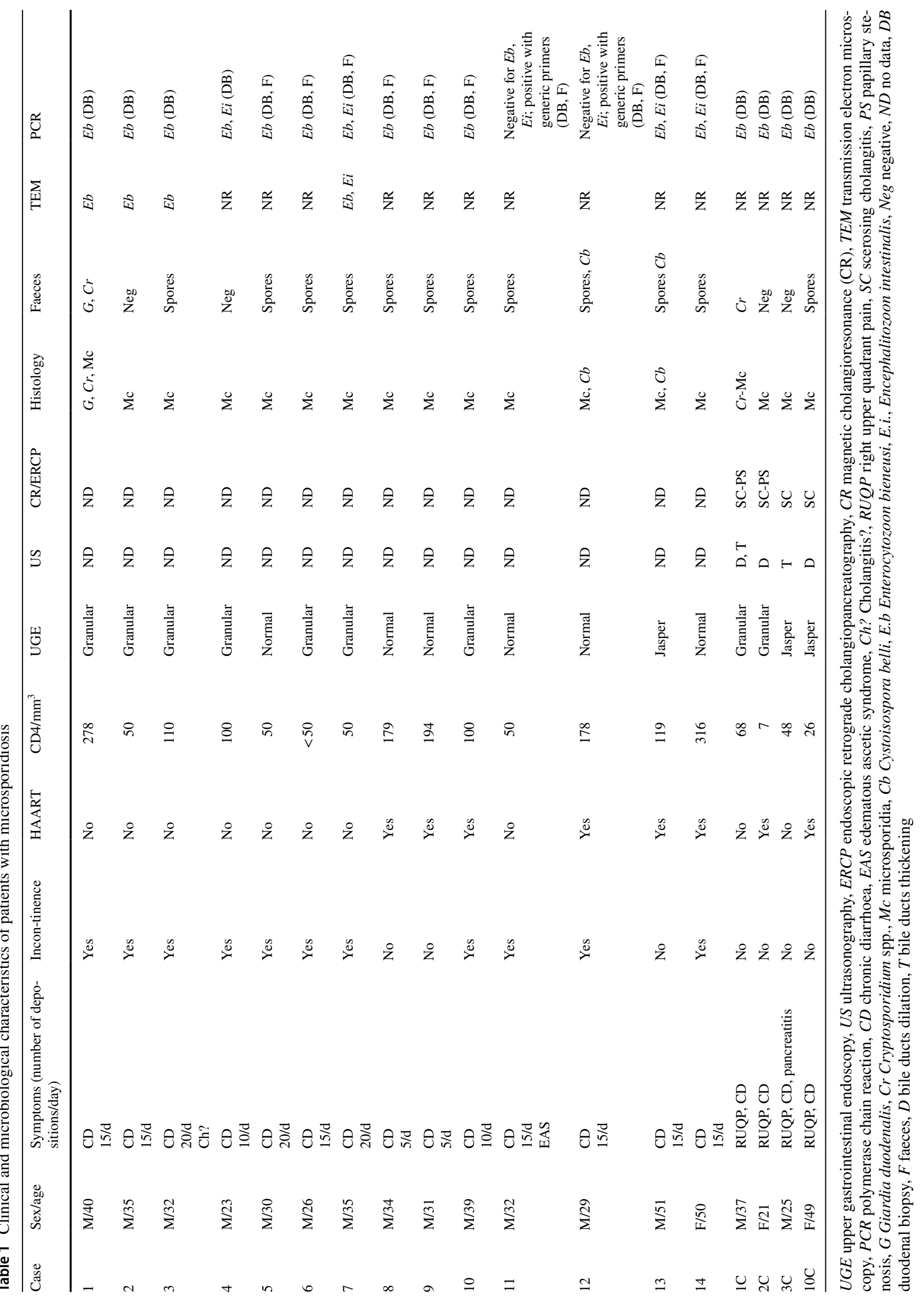


Table 2 Treatment and evolution of patients with microsporidiosis

\begin{tabular}{|c|c|c|c|c|c|c|c|}
\hline Case & Diarrhoea & $\begin{array}{l}\text { Adherence } \\
\text { to HAART }\end{array}$ & Specific treatment & $\begin{array}{l}\mathrm{CD} 4 / \mathrm{mm}^{3} \\
\text { value at } \\
\text { admission }\end{array}$ & $\begin{array}{l}\mathrm{CD} 4 / \mathrm{mm}^{3} \text { value } \\
\text { after treatment }\end{array}$ & Species identification & Survival \\
\hline 1 & Persisted & No & No & 278 & ND & $G, C r, E b$ & Died at day 35 \\
\hline 2 & Persisted & No & No & 50 & ND & $E b$ & Died at day 38 \\
\hline 3 & Persisted & No & Albendazole & 110 & ND & $E b$ & Died at day 49 \\
\hline 4 & Persisted & No & No & 100 & ND & $E b, E i$ & Died at day 40 \\
\hline 5 & Persisted & No & No & 50 & ND & $E b$ & Died at day 34 \\
\hline 6 & Resolved & No & Albendazole & $<50$ & ND & $E b$ & Died at day 100 \\
\hline 7 & Persisted & No & No & 50 & ND & $E b, E i$ & Died at day 12 \\
\hline 8 & Resolved & Yes & Albendazole & 179 & 314 & $E b$ & Discharged at day 7 \\
\hline 9 & Persisted & Yes & No & 194 & ND & $E b$ & Discharged at day 25 \\
\hline 10 & Persisted & Yes & Nitazoxanide & 100 & ND & $E b$ & Discharged at day 25 \\
\hline 11 & Persisted & No & Nitazoxanide & 50 & ND & $\mathrm{Mc}$ & Discharged at day 22 \\
\hline 12 & Resolved & Yes & $\begin{array}{l}\text { Albendazole, TMS- } \\
\text { SM }\end{array}$ & 178 & ND & $\mathrm{Mc}, C b, \operatorname{Sarc}$ & Died at 1 year \\
\hline 13 & Persisted & Yes & $\begin{array}{l}\text { Albendazole, clin- } \\
\text { damicin }\end{array}$ & 119 & ND & $E b, E i, C b$ & Discharged at day 37 \\
\hline 14 & Persisted & Yes & $\begin{array}{l}\text { Albendazole, nita- } \\
\text { zoxanide }\end{array}$ & 316 & 187 and later 396 & $E b, E i$ & Discharged at day 37 \\
\hline $1 \mathrm{C}$ & Persisted & No & No & 68 & ND & $C r, E b$ & Died at day 34 \\
\hline $2 \mathrm{C}$ & $\begin{array}{l}\text { Resolved and } \\
\text { relapsed } 4 \text { years } \\
\text { later }\end{array}$ & Yes & No & 7 & $<50$ & $E b$ & $\begin{array}{l}\text { Died at } 4 \text { years and } \\
4 \text { months }\end{array}$ \\
\hline $3 \mathrm{C}$ & Persisted & No & No & 48 & ND & $E b$ & Died at day 28 \\
\hline $10 \mathrm{C}$ & Persisted & Yes & Nitazoxanide & 26 & ND & $E b$ & Died at day 40 \\
\hline
\end{tabular}

G Giardia duodenalis, Cr Cryptosporidum spp., Mc microsporidia, Cb Cystoisospora belli, Sarc Sarcocystis sp., Eb Enterocytozoon bieneusi, Ei Encephalitozoon intestinalis, $N D$ no data

Fig. 1 Microsporidia spores in faeces observed by light microscopy. a Modified trichrome stain showing ovoid, pyriform or bacillar shaped-spores with bright pinkish red stained wall. b Gram-chromotrope stain showing spores of microsporidia with the presence of a vacuole or a diagonal band representing the polar tubule. Magnification $\times 1000$ (a)

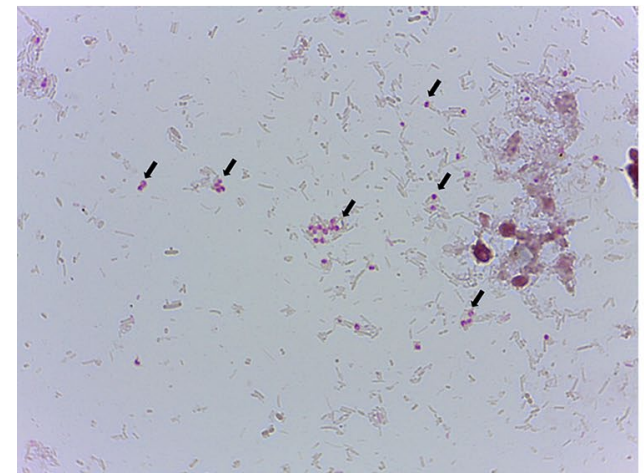

(b)

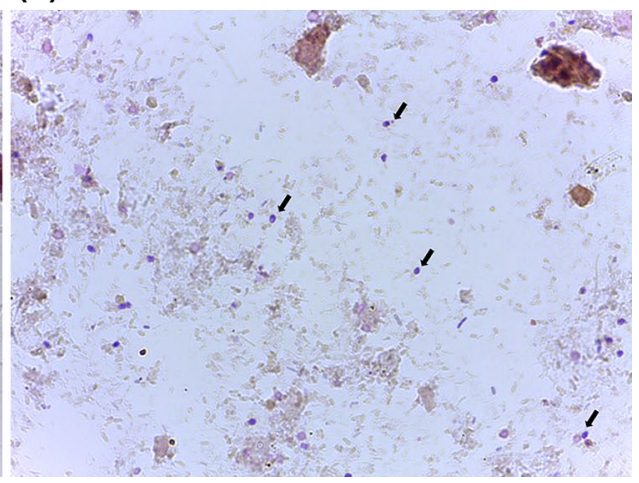

$\mathrm{mm}^{3}[3,7,27]$. Our patients correspond mainly to marginal population, prisoners, intravenous drug abusers, homeless, whose adherence to ART is very low. Due to these characteristics opportunistic infections continue to be frequent in the post ART era and microsporidiosis continues to be a cause of morbidity and mortality.

The diagnosis of microsporidia was positive in 18 out of the 143 cases representing $12.6 \%$, in concordance with previously described prevalence of microsporidia in HIV positive patients that varies between 7 and 50\% [104]. A recent meta-analysis [101] showed that the prevalence of microsporidia infection ranged between 0.7 and $81.3 \%$ in people with HIV with an estimated pooled prevalence of $11.8 \%$ worldwide and 5.6\% in Latin America. This last value represents only three studies that were done in Venezuela, Colombia and Perú $[25,41,90]$. Our present report is the first one in Argentina showing the prevalence of intestinal microsporidia infection, particularly in HIV-positive patient. 
(a)

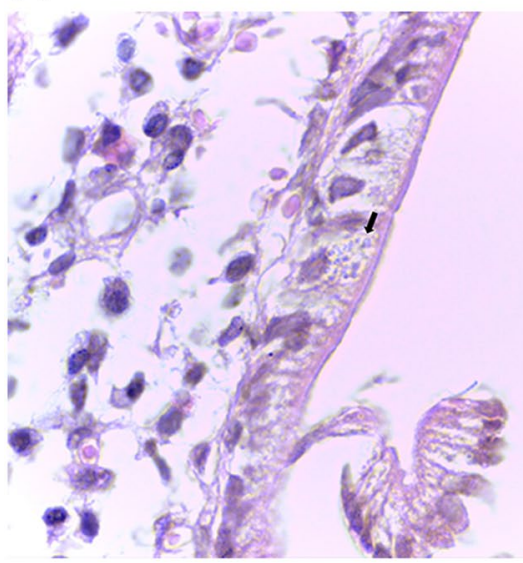

(c) (b)

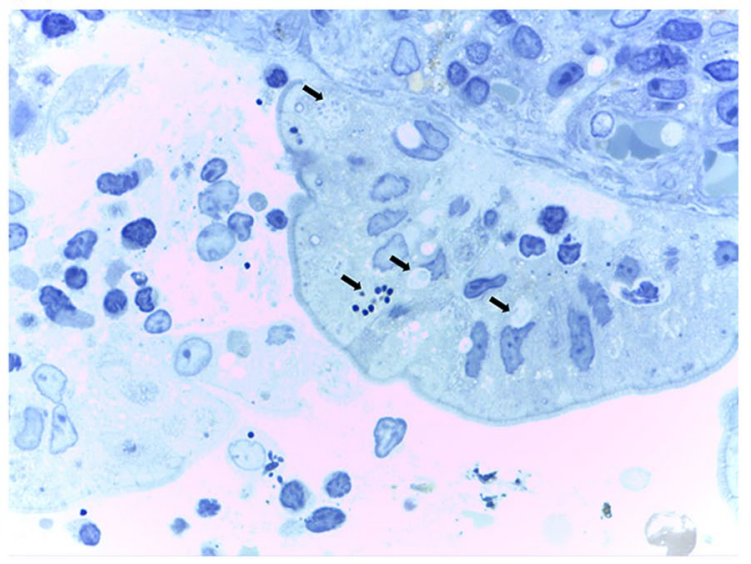

(d)
Fig. 2 Enterocytozoon bieneusi in biopsy specimens. a Spores with band-shaped or rounded clear structures inside (H\&E staining, magnification $\times 1000$ ). b Multiple intraepithelial spores and stages of oval or round shape in direct contact with the cytoplasm of the epithelial cell (Azure II staining, magnification $\times 1000$ ). $\mathbf{c}$ Epithelial cell

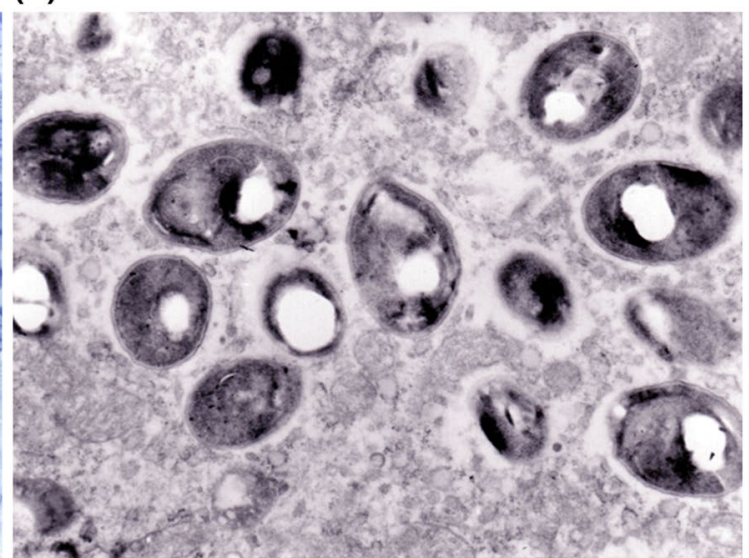

infected with spores leaving the epithelium and reaching the intestinal lumen (Azure II staining, magnification $\times 1000$ ). d Uninucleated spores of E. bieneusi in direct contact with the cytoplasm of host cells, in TEM (magnification $\times 5600$ ) (a)

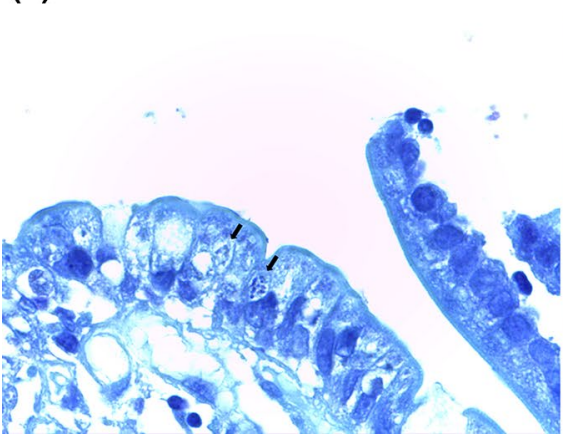

(b) (c)

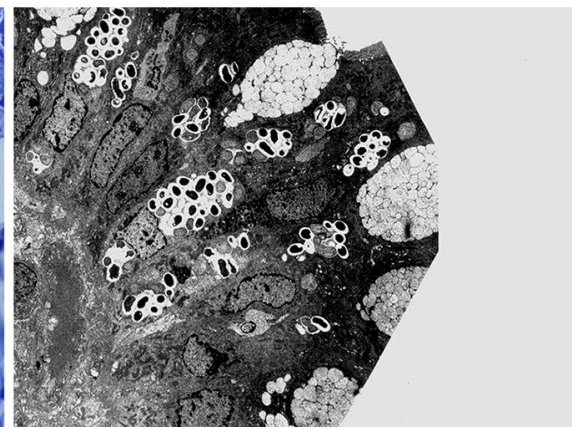

Fig. 3 Encephalitozoon intestinalis in biopsy specimens. a Spores with within displaced parasitophorous vacuoles (Giemsa stain, magnification $\times 1000$ ). b Merogony and/or sporogony stages surrounded

Most patients had chronic diarrhoea evolution of 3-12 months with an average of 5 months. Some authors by vacuoles (Azure II stain, magnification $\times 1000$ ). c Spores of $E$. intestinalis within parasitophorous vacuoles in TEM (magnification $\times 3300)$

described a broader range of 1-32 months with a higher average of 8 months [4]. The variable number of depositions 
per day was higher than that described in other reports which mentioned that most of patients had about five depositions/ day $[4,58]$. In our cases the number of depositions was ten or more per day. Diarrhoea was accompanied by weight loss in almost all patients studied being a similar finding as described by numerous authors [3, 4, 7, 27, 58]. A symptom that accompanies chronic diarrhoea in most of our patients was incontinence, which is not frequently observed [100].

The endoscopic appearance of the duodenal mucosa presented a granular appearance in $9 / 18$ cases and jasper in 3/18 cases. Changes in the appearance of the duodenal mucosa are not specific to an aetiologic agent since we observed them with different opportunistic infections (data not shown). In 6/18 cases the appearance of the duodenal mucosa was normal and biopsies allowed the identification of microsporidia. In patients with chronic diarrhoea, low CD4 level and normal endoscopic image sampling duodenal biopsy can identify aetiologic agents.

According to our results the diagnosis of microsporidiosis in patients with chronic diarrhoea should be present when it is accompanied by incontinence, weight loss and low CD4 cell count, and although VEDA shows a normal duodenal mucosa aspect, biopsy specimens' collection is also indicated.

HIV-associated cholangiopathy is characterized by abnormalities in the biliary tract in patients with low CD4 level [106]. The diagnosis of HIV-associated cholangiopathy was achieved in 11/143 of the studied patients reaching about $8 \%$. With the described methodology, microorganisms were identified in 10/11 cases. Other authors identified microorganisms only in $60 \%$ of cases [80]. The most common organisms identified in our patients with HIV-associated cholangiopathy were Cryptosporidium spp. and microsporidia. Microsporidia diagnosis was carried out in 4/11 cases reaching $37 \%$. Other authors identified microsporidia in about $10 \%$ of patients [1]. The only species identified in our series was E. bieneusi. Abdominal pain, diarrhoea, weight loss, and CD4 cell count was about 100 cells $/ \mathrm{mm}^{3}$ or lower occurred in all patients being similar to the description in the literature [80]. Abdominal ultrasonography allows to identify dilation and wall thickening of the common bile duct and other abnormalities in $75 \%$ of patients with HIV and cholangiopathy [11] and it was useful to identify abnormalities in all our cases.

In patients with microsporidiosis and cholangiopathy associated with E. bieneusi, the pattern of sclerosing cholangitis and papillary stenosis has been described [80]. All our patients had sclerosing cholangitis and two of them had also papillary stenosis.

Summarizing, the diagnosis of microsporidosis in patients with cholangiopathy must be present when vomiting and right upper quadrant pain are accompanied by increased alkaline phosphatase level, abdominal ultrasonography with dilated bile duct and/or thickened walls and CD4 cell count less than or equal 100 cells $/ \mathrm{mm}^{3}$. It may be accompanied by chronic diarrhoea.

Stool samples stained with modified trichrome and Gramchromotrope allowed the identification of spores in 13 of 143 cases constituting about $9 \%$ of cases. In similar studies in the United States, Brazil, Sweden and Thailand, prevalence between 9 and 33\% was observed [100, 105]. The use of both staining techniques together was very useful since in some samples stained with modified trichrome spores resembled bacteria and yeast and Gram-chromotrope technique allowed us to differentiate.

Duodenal biopsy samples stained with Giemsa, H\&E and Azure II helped to identify microsporidia-compatible structures by light microscopy in more than $12 \%$ of cases. In Italy, in a study including 21 patients with AIDS and chronic diarrhoea in duodenal biopsies stained with $\mathrm{H} \& \mathrm{E}$ and toluidine blue microsporidia were identified with security in two cases $(9.52 \%)$ and were suspected in 3 cases [10]. In another study of 59 patients with AIDS and chronic diarrhoea in duodenal biopsies stained with $\mathrm{H} \& \mathrm{E}$ and Giemsa, diagnosis of microsporidia was performed in 8 patients reaching $13 \%$ [79]. However, in a study in Rio de Janeiro in Brazil in 40 patients with chronic diarrhoea and AIDS which underwent duodenal biopsies stained with H\&E and Giemsa microsporidia were diagnosed in 11 cases reaching $27.5 \%$ [13]. Other authors performed the diagnosis of microsporidia in duodenal biopsies in patients with diarrhoea in $30 \%$ of cases [81]. In our study identifying structures compatible with microsporidia by light microscopy in $12.6 \%$ of cases could be real or underestimated. The variable sensitivity of the light microscopy in different reports could be given by the focal distribution of infected enterocytes and selected sites for biopsies that may or may not correspond to infected cells $[13,65]$. Another possibility is the difficulty in identifying structures compatible with microsporidia in cases with low parasite burden $[10,65]$. Numerous studies agree that the identification of intracellular stages compatible with microsporidia depends on careful observation and interpretation of histopathology [4, 46, 64]. Some authors suggest re-observation of histological slides if microsporidian suggestive microorganisms are present [4]. This difficulty in identifying compatible parasitic structures with microsporidia using $\mathrm{H} \& \mathrm{E}$ and Giemsa was mentioned by different authors [4, $10,13,46,65,76]$. One reason is that while the spores are easier to identify, it is not so with other parasitic stages given the minimal contrast between the parasitic structure and the cytoplasm of the infected cell $[46,65]$. The thickness of the slices is another factor because the better definition of the structures is obtained with thin slices. Some authors suggest that slices of $3 \mu \mathrm{m}$ in thickness are useful for identifying microsporidia in H\&E and Giemsa stained samples [65]. In our work parasitic stages were identified in 14 duodenal 
biopsies embedded in polybedaraldita, sliced in semi-thin sections of $1 \mu \mathrm{m}$ and stained with Azure II. The use of semithin sections allowed us to get a better definition of parasitic and cellular stages using light microscopy. Our findings in semi-thin sections were similar to the recommendations of different authors for the identification of microsporidia [46, $65,74,76]$.

A mixed villi pattern was observed in almost all patients (17/18 cases). Villous atrophy and crypt hyperplasia were observed in all patients. Other authors have also described the villus atrophy and crypt hyperplasia as a frequent finding $[11,58,74,77,82]$. However, some microsporidosis reported cases presented without villous atrophy [10]. The increased intraepithelial lymphocytic infiltrates were found in some patients (4/14 cases), similar as described by other authors $[58,74,79,82]$. The infiltrate in lamina propria with mononuclear predominance in most cases is a common finding [58].

Although TEM is the best method to identify structures and differentiate species, it is time-consuming, expensive, with low sensitivity and is not available in all centres precluding its use as routine [56, 74-76]. In this way, molecular methods have gained a main role in the identification of microsporidia at the species level. The target sequences of PCR most commonly used in the diagnosis and identification of microsporidia species that infect humans correspond to fragments of rRNA genes, with greater emphasis on the small subunit and the ITS. The PCR primers were selected for an amplification product of less than $1000 \mathrm{bp}$, improving diagnosis in formalin-fixed samples [85]. Therefore, we employed the primer set Eb.gt::Eb.gc with an amplification product of $210 \mathrm{bp}$ to identify the species E. bieneusi and the set SINTF1::SINTR with an amplification product of $520 \mathrm{bp}$ to identify E. intestinalis $[31,96]$. The main advantage of using the method of PCR in faecal samples is that it is a noninvasive method that allows the differentiation of species of microsporidia, which is useful in therapy administration. The use of PCR in faecal samples allows detection of infections with more than one species of microsporidia as microscopic observation of spores in faeces does not.

Coinfection of E. bieneusi and E. intestinalis was first described in a patient in 1992 [8]. In our work four cases coinfected with both species were identified. Other authors showed that coinfection with both species is not uncommon since they identified it in $9.6 \%$ of cases [49].

The interpretation of the clinical manifestations, the use of imaging techniques, the application of methods of etiological diagnosis by microscopy in stool and biopsy samples and the use of molecular tools applied to different biological specimens, enabled, by the systematic and integrated employment, the diagnosis and identification of species of microsporidia in patients with AIDS, chronic diarrhoea and/ or HIV-associated cholangiopathy.

\section{References}

1. Abdalian R, Heathcote EJ (2006) Sclerosing cholangitis: a focus on secondary causes. Hepatology 44:1063-1074

2. Aissa S, Chabchoub N, Abdelmalek R, Kanoun F, Goubantini A, Ammari L, Kilani B, Bouratbine A, Tiouiri-Ben Aissa H, Aoun $\mathrm{K}$ (2017) Asymptomatic intestinal carriage of microsporidia in HIV-positive patients in Tunisia: prevalence, species, and pathogenesis. Med Sante Trop 27:281-285. https://doi.org/10.1684/ mst.2017.0697

3. Anastasi JK, Capili B (2000) HIV and diarrhea in the era of HAART: 1998 New York state hospitalizations. Am J Infect Control 28:262-266

4. Asmuth DM, DeGirolami PC, Federman M, Ezratty CR, Pleskow DK, Desai G, Wanke CA (1994) Clinical features of microsporidosis in patients with AIDS. Clin Infect Dis 18:819-825

5. Bartholomew JW (1981) Stains for microorganisms in sections. In: Clark G (ed) Staining procedures, 4th edn. Williams \& Wilkins, Baltimore, pp 441-473

6. Bednarska M, Jankowska I, Pawelas A, Piwczyńska K, Bajer A, Wolska-Kuśnierz B, Wielopolska M, Welc-Falęciak R (2018) Prevalence of Cryptosporidium, Blastocystis, and other opportunistic infections in patients with primary and acquired immunodeficiency. Parasitol Res 117:2869-2879. https://doi. org/10.1007/s00436-018-5976-6

7. Bini EJ, Cohen J (1998) Diagnostic yield and cost-effectiveness of endoscopy in chronic human immunodeficiency virus-related diarrhea. Gastrointest Endosc 48:354

8. Blanshard C, Ellis DS, Tovey DG, Dowell S, Gazzard BG (1992) Treatment of intestinal microsporidiosis with albendazole in patients with AIDS. AIDS 6:311-313

9. Blanshard C, Francis N, Gazzard BG (1996) Investigation of chronic diarrhoea in acquired immunodeficiency syndrome. A prospective study of 155 patients. Gut 39:824-832

10. Boldorini R, Tosoni A, Mazzucco G, Cernuschi M, Caramello P, Maran E, Costanzi G, Monga G (1996) Intracellular protozoan infection in small intestinal biopsies of patients with AIDS. Pathol Res Pract 192:249-259

11. Bouche H, Housset C, Dumont JL, Carnot F, Menu Y, Aveline B, Belghiti J, Boboc B, Erlinger S, Berthelot P (1993) AIDSrelated cholangitis: diagnostic features and course in 15 patients. J Hepatol 17:34-39

12. Bozzola J, Russel LD (1999) Specimens preparation for transmission electron microscopy. In: Bozzola J, Russel LD (eds) Electron microscopy: principles and techniques for biologist, 2nd edn. Jones and Bartlett Publishers, Sudbury, pp 16-47

13. Brasil P, de Lima DB, de Paiva DD, Lobo MS, Sodre FC, da Silva SP, Verissimo-Villela E, da Silva EJ, Peralta JM, Morgado M, Moura H (1999) Emerging and opportunistic intestinal parasites in HIV-infected patients with chronic diarrhea in Rio de Janeiro, Brazil. J Eukaryot Microbiol 46:40S-41S

14. Brasil P, de Lima DB, de Paiva DD, Lobo MS, Sodré FC, Silva SP, Villela EV, Silva EJ, Peralta JM, Morgado M, Moura H (2000) Clinical and diagnostic aspects of intestinal microsporidiosis in HIV-infected patients with chronic diarrhea in Rio de Janeiro, Brazil. Rev Inst Med Trop Sao Paulo 42:299-304

15. Bryan RT, Schwartz DA (1999) Epidemiology of microsporidiosis. In: Wittner M, Weiss LM (eds) The microsporidia and microsporidiosis. A.M.S. Press, Washington DC, pp 502-516

16. Cali A, Becnel JJ, Takvorian PM (2017) Microsporidia. In: Archibald JM, Simpson AGB, Slamovits CH (eds) Handbook of the protists. Publisher Springer International Publishing AG, Cham, pp 1559-1618

17. Cali A, Kotler DP, Orenstein JM (1993) Septata intestinalis n.g., n. sp., an intestinal microsporidian associated with chronic 
diarrhea and dissemination in AIDS patients. J Eukaryot Microbiol 40:101-112

18. Canning EU (1993) Microsporidia. In: Kreier JP, Baker JR (eds) Parasitic protozoa. Academic Press, New York, pp 299-385

19. Canning EU, Lom J (1986) The microsporidia of vertebrates. Academic, London

20. Carnevale S, Velásquez JN, Labbé JH, Chertcoff A, Cabrera MG, Rodríguez MI (2000) Diagnosis of Enterocytozoon bieneusi by PCR in stool samples eluted from filter paper disks. Clin Diagn Lab Immunol 7:504-506

21. Carville A, Mansfield K, Widmer G, Lackner A, Kotler D, Wiest P, Gumbo T, Sarbah S, Tzipori S (1997) Development and application of genetic probes for detection of Enterocytozoon bieneusi in formalin-fixed stools and in intestinal biopsy specimens from infected patients. Clin Diagn Lab Immunol 4:405-408

22. Cello JP (1989) Acquired immunodeficiency syndrome cholangiopathy: spectrum of disease. Am J Med 86:539-546

23. Cello JP, Day LW (2009) Idiopathic AIDS enteropathy and treatment of gastrointestinal opportunistic pathogens. Gastroenterology 136:1952-1965. https://doi.org/10.1053/j.gastr o.2008.12.073

24. Cello JP (1997) Hepatobiliary manifestations in AIDS. In: Podolsky DK, Friedman LS (eds) Gastroenterology in the centennial year and beyond. AGA, Washington DC, pp 399-403

25. Chacin-Bonilla L, Panunzio AP, Monsalve-Castillo FM, ParraCepeda IE, Martinez R (2006) Microsporidiosis in Venezuela: prevalence of intestinal microsporidiosis and its contribution to diarrhea in a group of human immunodeficiency virus-infected patients from Zulia state. Am J Trop Med Hyg 74:482-486

26. Choudhary MM, Metcalfe MG, Arrambide K, Bern C, Visvesvara GS, Pieniazek NJ, Bandea RD, Deleon-Carnes M, Adem P, Choudhary MM, Zaki SR, Saeed MU (2011) Tubulinosema sp. microsporidian myositis in immunosuppressed patient. Emerg Infect Dis 17:1727-1730. https://doi.org/10.3201/eid17 09.101926

27. Cohen J, West AB, Bini EJ (2001) Infectious diarrhea in human immunodeficiency virus. Gastroenterol Clin N Am 30:637-664

28. Conteas CN, Berlin OG, Lariviere MJ, Pandhumas SS, Speck CE, Porschen R, Nakaya T (1998) Examination of the prevalence and seasonal variation of intestinal microsporidiosis in the stools of persons with chronic diarrhea and human immunodeficiency virus infection. Am J Trop Med Hyg 58:559-561

29. Coyle CM, Wittner M, Kotler DP, Noyer C, Orenstein JM, Tanowitz HB, Weiss M (1996) Prevalence of microsporidiosis due to Enterocytozoon bieneusi and Encephalitozoon (Septata) intestinalis among patients with AIDS-related diarrhea: determination by the polymerase chain reaction to the microsporidian small subunit-rRNA gene. Clin Infect Dis 23:1002-1006

30. Curgy JJ, Vavra J, Vivares C (1980) Presence of ribosomal RNAs with prokaryotic properties in microsporidia, eukaryotic organisms. Biol Cell 38:49-51

31. da Silva AJ, Schwartz DA, Visvesvara GS, de Moura H, Slemenda SB, Pieniazek NJ (1997) Detection of Septata intestinalis (Microsporidia) Cali et al. 1993 using polymerase chain reaction primers targeting the small submit subunit ribosomal RNA coding region. Mol Diagn 2:47-52

32. da Silva AJ, Schwartz DA, Visvesvara GS et al (1996) Sensitive PCR diagnosis of infections by Enterocytozoon bieneusi (microsporidia) using primers based on the region coding for small-subunit rRNA. J Clin Microbiol 34(4):986-987

33. David F, Schuitema AR, Sarfati C, Liguory O, Hartskeerl RA, Derouin F, Molina JM (1996) Detection and species identification of intestinal microsporidia by polymerase chain reaction in duodenal biopsies from human immunodeficiency virus-infected patients. J Infect Dis 174:874-877
34. del Aguila C, Lopez-Velez R, Fenoy S, Turrientes C, Cobo J, Navajas R, Visvesvara GS, Croppo GP, da Silva AJ, Pieniazek NJ (1997) Identification of Enterocytozoon bieneusi spores in respiratory samples from an AIDS patient with 2-year history of intestinal microsporidiosis. J Clin Microbiol 35:1862-1866

35. Devarbhavi H, Sebastian T, Seetharamu SM, Karanth D (2010) HIV/AIDS cholangiopathy: clinical spectrum, cholangiographic features and outcome in 30 patients. J Gastroenterol Hepatol 25:1656-1660. https://doi.org/10.1111/j.1440-1746.2010.06336.x

36. Dickson BC, Streutker CJ, Chetty R (2006) Coeliac disease: an update for pathologists. J Clin Pathol 59:1009-1016

37. Eeftinck Schattenkerk JK, van Gool T, van Ketel RJ, Bartelsman JF, Kuiken CL, Terpstra WJ, Reiss P (1991) Clinical significance of small-intestinal microsporidiosis in HIV-1-infected individuals. Lancet 337:895-898

38. Espern A, Morio F, Miegeville M, Illa H, Abdoulaye M, Meyssonnier V, Adehossi E, Lejeune A, Cam PD, Besse B, GayAndrieu F (2007) Molecular study of microsporidiosis due to Enterocytozoon bieneusi and Encephalitozoon intestinalis among human immunodeficiency virus-infected patients from two geographical areas: Niamey, Niger, and Hanoi, Vietnam. J Clin Microbiol 45:2999-3002

39. Fayer R, Santin-Duran M (2014) Epidemiology of micro-sporidia in human infections. In: Weiss L, Becnel JJ (eds) Microsporidia: pathogens of opportunity. Wiley, New Yersey, pp 135-164

40. Fletcher SM, Stark D, Harkness J, Ellis J (2012) Enteric protozoa in the developed world: a public health perspective. Clin Microbiol Rev 25:420-449. https://doi.org/10.1128/CMR.05038-11

41. Flórez AC, García DA, Moncada L, Beltrán M (2003) Prevalence of microsporidia and other intestinal parasites in patients with HIV infection, Bogota, 2001. Biomedica 23:274-282

42. Franzen C, Kuppers R, Müller A et al (1996) Genetic evidence for latent Septata intestinalis infection in human immunodeficiency virus-infected patients with intestinal microsporidiosis. J Infect Dis 173(4):1038-1040

43. Franzen C, Müller A (1999) Cryptosporidia and Microsporidiawaterborne diseases in the immunocompromised host. Diagn Microbiol Infect Dis 34:245-262

44. Franzen C, Müller A, Hartmann P, Kochanek M, Diehl V, Fätkenheuer G (1996) Disseminated Encephalitozoon (Sepatata) intestinalis infection in a patient with AIDS. N Engl J Med 335:1610-1611

45. Franzen C, Müller A, Hegener P, Salzberger B, Hartmann P, Fätkenheuer G, Diehl V, Schrappe M (1995) Detection of microsporidia (Enterocytozoon bieneusi) in intestinal biopsy specimens from human immunodeficiency virus-infected patients by PCR. J Clin Microbiol 33:2294-2296

46. Garcia LS (2002) Laboratory identification of the microsporidia. J Clin Microbiol 40:1892-1901

47. Gazzard B, Blanshard C (1993) Diarrhoea in AIDS and other immunodeficiency states. Baillieres Clin Gastroenterol $7: 387-419$

48. Ghoyounchi R, Mahami-Oskouei M, Rezamand A, Spotin A, Aminisani N, Nami S, Pirestani M, Berahmat R, Madadi S (2019) Molecular phylodiagnosis of Enterocytozoon bieneusi and Encephalitozoon intestinalis in children with cancer: microsporidia in malignancies as an emerging opportunistic infection. Acta Parasitol. https://doi.org/10.2478/s11686-01800012-w (epub ahead of print)

49. Graczyk TK, Johansson MA, Tamang L, Visvesvara GS, Moura LS, DaSilva AJ, Girouard AS, Matos O (2007) Retrospective species identification of microsporidian spores in diarrheic fecal samples from human immunodeficiency virus/AIDS patients by multiplexed fluorescence in situ hybridization. $\mathbf{J}$ Clin Microbiol 45:1255-1260 
50. Greigert V, Pfaff AW, Abou-Bacar A, Candolfi E, Brunet J (2018) Intestinal microsporidiosis in Strasbourg from 2014 to 2016: emergence of an Enterocytozoon bieneusi genotype of Asian origin. Emerg Microbes Infect 7:97. https://doi. org/10.1038/s41426-018-0099-9

51. Hassan NA, Lim YAL, Mahmud R, Mohd-Shaharuddin N, Wan Sulaiman WY, Ngui R (2018) Molecular diagnosis of microsporidia among immunocompromised patients in Kuala Lumpur, Malaysia. Am J Trop Med Hyg 99:1562-1566. https ://doi.org/10.4269/ajtmh.17-0901

52. Hutin YJ, Sombardier MN, Liguory O, Sarfati C, Derouin F, Modaï J, Molina JM (1998) Risks factors for intestinal microsporidiosis in patients infected with human immunodeficiency virus. J Infect Dis 178:904-907

53. Ishihara R, Hayashi Y (1968) Some properties of ribosomes from the sporoplasm of Nosema bombysis. J Invertebr Pathol 11:377-385

54. Kearney DJ, Steuerwald M, Koch J (1999) A prospective study of endoscopy in HIV associated diarrhea. Am J Gastroenterol 94:596-602

55. Kim LS, Hadley WK, Stansell J, Cello JP, Koch J (1998) Declining prevalence of cryptosporidiosis in San Francisco. Clin Infect Dis 27:655-656

56. Kotler DP, Orenstein JM (1995) Microsporidia. In: Blaser MJ, Smith PD, Ravdin JI, Greenberg HB, Guerrant RL (eds) Infections of the gastrointestinal tract. Raven Press, New York, pp $1129-1140$

57. Kotler DP, Orenstein JM (1997) Clinical syndromes associated with microsporidiosis. In: Chandler FW, Schwartz DA, Manz HJ, Lack EE (eds) Pathology of infectious diseases. Appleton \& Lange, Stamford, pp 258-292

58. Kotler DP, Orenstein JM (1998) Clinical syndromes associated with microsporidiosis. Adv Parasitol 40:321-349

59. Kotler DP, Orenstein JM (1999) Clinical syndromes associated with microsporidiosis. In: Wittner M, Weiss LM (eds) The microsporidia and microsporidiosis. A.M.S. Press, Washington DC, pp 258-292

60. Li W, Feng Y, Santin M (2019) Host specificity of Enterocytozoon bieneusi and public health implications. Trends Parasitol 35:436-451. https://doi.org/10.1016/j.pt.2019.04.004

61. Liguory O, David F, Sarfati C, Schuitema AR, Hartskeerl RA, Derouin F, Modaï J, Molina JM (1997) Diagnosis of infections caused by Enterocytozoon bieneusi and Encephalitozoon intestinalis using polymerase chain reaction in stool specimens. AIDS 11:723-726

62. Mansfield KG, Carville A, Shvetz D, MacKey J, Tzipori S, Lackner AA (1997) Identification of an Enterocytozoon bieneusi-like microsporidian parasite in simian-immunodeficiency-virus-inoculated macaques with hepatobiliary disease. Am J Pathol 150:1395-1405

63. Maratka Z (1984) Terminology, definitions and diagnostic criteria in digestive endoscopy. With the collaboration of the members of the Terminology Committee of the World Society of Digestive Endoscopy/OMED. Scand J Gastroenterol Suppl 103:1-74

64. McWilliam LJ, Curry A (1990) Intestinal microsporidiosis in AIDS. J Clin Pathol 43:173-174

65. Michiels JF, Hofman P, Saint Paul MC, Loubière R, Bernard E, LeFichoux Y (1993) Pathological features of intestinal microsporidiosis in HIV positive patients: a report of 13 new cases. Pathol Res Pract 189:377-383

66. Mönkemüller KE, Call SA, Lazenby AJ, Wilcox CM (2000) Declining prevalence of opportunistic gastrointestinal disease in the era of combination antiretroviral therapy. Am J Gastroenterol 95:457-462
67. Morio F, Poirier P, Le Govic Y, Laude A, Valot S, Desoubeaux G, Argy N, Nourrisson C, Pomares C, Machouart M, Dalle F, Botterel F, Bourgeois N, Cateau E, Leterrier M, Beser J, Lavergne RA, Le Pape P (2019) Assessment of the first commercial multiplex PCR kit (ParaGENIE Crypto-Micro RealTime PCR) for the detection of Cryptosporidium spp., Enterocytozoon bieneusi, and Encephalitozoon intestinalis from fecal samples. Diagn Microbiol Infect Dis. https://doi.org/10.1016/j. diagmicrobio.2019.04.004

68. Moura H, Da Silva JL, Sodré FC, Brasil P, Wallmo K, Wahlquist S, Wallace S, Croppo GP, Visvesvara GS (1996) Gramchromotrope: a new technique that enhaces detection of microsporidial spores in clinical samples. J Eukaryot Microbiol 43:94S-95S

69. Nasarudin SN, Zainudin NS, Bernadus M, Nawi AM, Hanafiah A, Osman E (2015) Loop-mediated isothermal amplification for rapid molecular detection of Enterocytozoon bieneusi in faecal specimens. J Med Microbiol 64:1329-1334

70. Nooshadokht M, Sharifi I, Mohammadi MA, Pirestani M, Afgar A, Mahootchi A, Salari S (2017) Intestinal microsporidiosis in Iran: infection in immune-compromised and immunocompetent patients. Curr Med Mycol 3:30-36. https://doi. org/10.18869/acadpub.cmm.3.1.30

71. Ombrouck C, Ciceron L, Biligui S, Brown S, Marechal P, van Gool T, Datry A, Danis M, Desportes-Livage I (1997) Specific PCR assay for direct detection of intestinal microsporidia Enterocytozoon bieneusi and Encephalitozoon intestinalis in fecal specimens from human immunodeficiency virus-infected patients. J Clin Microbiol 35:652-655

72. Ombrouck C, Ciceron L, Desportes-Livage I (1996) Specific and rapid detection of Microsporidia in stool specimens from AIDS patients by PCR. Parasite 3:85-86

73. Ombrouck C, Desportes-Livage I, Achbarou A, Gentilini M (1996) Specific detection of microsporidia Encephalitozoon intestinalis in AIDS patients. C R Acad Sci III 319:39-43

74. Orenstein JM (1991) Microsporidiosis in the acquired immunodeficiency syndrome. J Parasitol 77:843-864

75. Orenstein JM (1997) Microsporidiosis. In: Chandler FW, Schwartz DA, Manz HJ, Lack EE (eds) Pathology of infectious diseases. Appleton \& Lange, Stamford, pp 1223-1239

76. Orenstein JM, Chiang J, Steinberg W, Smith PD, Rotterdam H, Kotler DP (1990) Intestinal microsporidiosis as cause of diarrhea in human immunodeficiency virus-infected patients: a report of 20 cases. Hum Pathol 21:475-481

77. Orenstein JM, Tenner M, Kotler DP (1992) Localization of infection by microsporidian Enterocytozoon bieneusi in the gastrointestinal tract of AIDS patients with diarrhea. AIDS 6:195-197

78. Pariyakanok L, Satitpitakul V, Putaporntip C, Jongwutiwes S (2015) Femtosecond laser-assisted anterior lamellar keratoplasty in stromal keratitis caused by an Endoreticulatus-like microsporidia. Cornea 34:588-591. https://doi.org/10.1097/ICO.00000 00000000392

79. Peacock CS, Blanshard C, Tovey DG, Ellis DS, Gazzard BG (1991) Histological diagnosis of intestinal microsporidiosis in patients with AIDS. J Clin Pathol 44:558-563

80. Pol S, Romana CA, Richard S, Amouyal P, Desportes-Livage I, Carnot F, Pays JF, Berthelot P (1993) Microsporidia infection in patients with the human immunodeficiency virus and unexplained cholangitis. N Engl J Med 328:95-99

81. Rabeneck L, Genta RM, Gyorkey F, Clarridge JE, Gyorkey P, Foote LW (1995) Observations on the pathological spectrum and clinical course of microsporidiosis in men infected with the human immunodeficiency virus: follow-up study. Clin Infect Dis 20:1229-1235

82. Rijpstra AC, Canning EU, Van Ketel RJ, Eeftinck Schattenkerk JK, Laarman JJ (1988) Use of light microscopy to diagnose 
small-intestinal microsporidiosis in patients with AIDS. J Infect Dis 157:827-831

83. Rinder H, Janitschke K, Aspöck H, Da Silva AJ, Deplazes P, Fedorko DP, Franzen C, Futh U, Hünger F, Lehmacher A, Meyer CG, Molina JM, Sandfort J, Weber R, Löscher T (1998) Blinded, externally controlled multicenter evaluation of light microscopy and PCR for detection of microsporidia in stool specimens. The Diagnostic Multicenter Study Group on Microsporidia. J Clin Microbiol 36:1814-1818

84. Sabrá A, Madi K (1994) Correlação clínica e estudo estereomicroscópico e histológico da mucosa intestinal. In: Sabrá A (ed) Diarréia Aguda e Crônica em Pediatria. Quarta edição. Editora Cultura medica, Rio de Janeiro, pp 82-92

85. Shibata D (1994) Extraction of DNA from paraffin-embedded tissue for analysis by polymerase chain reaction: new tricks from an old friend. Hum Pathol 25:561-563

86. Sodré FC (1996) Microsporidioses humanas: desenvolvimento de métodos para o diagnóstico morfológico das microsporidioses intestinais em pacientes HIV-positivos no município do Rio de Janeiro (Master's thesis). Instituto Oswaldo Cruz-Fiocruz, Rio de Janeiro

87. Sokolova OI, Demyanov AV, Bowers LC, Didier ES, Yakovlev AV, Skarlato SO, Sokolova YY (2011) Emerging microsporidian infections in Russian HIV-infected patients. J Clin Microbiol 49:2102-2108. https://doi.org/10.1128/JCM.02624-10

88. Sprague V, Becnel JJ, Hazard EI (1992) Taxonomy of the phylum microspora. Crit Rev Microbiol Rev 18:285-395

89. Stentiford GD, Becnel -J, Weiss LM, Keeling PJ, Didier ES, Williams BP, Bjornson S, Kent ML, Freeman MA, Brown MJF, Troemel ER, Roesel K, Sokolova Y, Snowden KF, Solter L (2016) Microsporidia-emergent pathogens in the global food chain. Trends Parasitol 32:336-348. https://doi.org/10.1016/j. pt.2015.12.004

90. Sulaiman IM, Bern C, Gilman R, Cama V, Kawai V, Vargas D, Ticona E, Vivar A, Xiao L (2003) A molecular biologic study of Enterocytozoon bieneusi in HIV-infected patients in Lima, Peru. J Eukaryot Microbiol 50(Suppl):591-596

91. Talal AH, Kotler DP, Orenstein JM, Weiss LM (1998) Detection of Enterocytozoon bieneusi in fecal specimens by polymerase chain reaction analysis with primers to the small-subunit rRNA. Clin Infect Dis 26:673-675

92. Taniuchi M, Verweij JJ, Sethabutr O, Bodhidatta L, Garcia L, Maro A, Kumburu H, Gratz J, Kibiki G, Houpt ER (2011) Multiplex polymerase chain reaction method to detect Cyclospora, Cystoisospora, and Microsporidia in stool samples. Diagn Microbiol Infect Dis 71:386-390. https://doi.org/10.1016/j.diagmicrob io.2011.08.012

93. Telemann W (1908) Eine methode zur erleichterung der auffindung von parasiteneiern in den faeces. Dtsch Med Wochenschr 35:1510-1511

94. Tumwine JK, Kekitiinwa A, Bakeera-Kitaka S, Ndeezi G, Downing R, Feng X, Akiyoshi DE, Tzipori S (2005) Cryptosporidiosis and microsporidiosis in Ugandan children with persistent diarrhea with and without concurrent infection with the human immunodeficiency virus. Am J Trop Med Hyg 73:921-925

95. van Gool T, Vetter JC, Weinmayr B, Van Dam A, Derouin F, Dankert J (1997) High seroprevalence of Encephalitozoon species in immunocompetent subjects. J Infect Dis 175:1020-1024

96. Velásquez JN, Carnevale S, Guarnera EA, Labbé JH, Chertcoff A, Cabrera MG, Rodríguez MI (1996) Detection of the microsporidian parasite Enterocytozoon bieneusi in specimens from patients with AIDS by PCR. J Clin Microbiol 34:3230-3232
97. Velásquez JN, Carnevale S, Oelemann WM, Etchart C, Peralta JM (2005) Diagnosis of Enterocytozoon bieneusi by the polymerase chain reaction in archival fixed duodenal tissue. Enferm Infecc Microbiol Clin 23:218-220

98. Velásquez JN, Chertcoff AV, Etchart C, di Risio C, Sodré FC, Cucher MA, Carnevale S (2012) First case report of infection caused by Encephalitozoon intestinalis in a domestic cat and a patient with AIDS. Vet Parasitol 190:583-586. https://doi. org/10.1016/j.vetpar.2012.06.034

99. Verweij JJ, Ten Hove R, Brienen EA, van Lieshout L (2007) Multiplex detection of Enterocytozoon bieneusi and Encephalitozoon spp. in fecal samples using real-time PCR. Diagn Microbiol Infect Dis 57:163-167

100. Wanachiwanawin D, Manatsathit S, Lertlaituan P, Thakerngpol K, Suwanagool P (1998) Intestinal microsporidiosis in HIV infected patients with chronic diarrhea in Thailand. Southeast Asian J Trop Med Public Health 29:767-771

101. Wang ZD, Liu Q, Liu HH, Li S, Zhang L, Zhao YK, Zhu XQ (2018) Prevalence of Cryptosporidium, microsporidia and Isospora infection in HIV-infected people: a global systematic review and meta-analysis. Parasit Vectors 11:28. https://doi.org/10.1186/ s13071-017-2558-x

102. Watts MR, Chan RC, Cheong EY, Brammah S, Clezy KR, Tong C, Marriott D, Webb CE, Chacko B, Tobias V, Outhred AC, Field AS, Prowse MV, Bertouch JV, Stark D, Reddel SW (2014) Anncaliia algerae microsporidial myositis. Emerg Infect Dis 20:185-191. https://doi.org/10.3201/eid2002.131126

103. Weber R, Bryan RT, Owen RL, Wilcox CM, Gorelkin L, Visvesvara GS (1992) Improved light-microscopical detection of microsporidia spores in stool and duodenal aspirates. $\mathrm{N}$ Engl $\mathrm{J}$ Med 326:161-166

104. Weber R, Bryan RT, Schwartz DA, Owen RL (1994) Human microsporidial infections. Clin Microbiol Rev 7:426-461

105. Weber R, Sauer B, Spycher MA, Deplazes P, Keller R, Ammann R, Briner J, Lüthy R (1994) Detection of Septata intestinalis in stool specimens and coprodiagnostic monitoring of successful treatment with albendazole. Clin Infect Dis 19:342-345

106. Weiss LM, Vossbrinck CR (1998) Microsporidiosis: molecular and diagnostic aspects. Adv Parasitol 40:351-395

107. Wilcox CM, Rabeneck L, Friedman S (1996) AGA technical review: malnutrition and cachexia, chronic diarrhea and hepatobiliary disease in patients with human immunodeficiency virus infection. Gastroenterology 111:1724-1736

108. Willson R, Harrington R, Stewart B, Fritsche T (1995) Human immunodeficiency virus 1 - associated necrotizing cholangitis caused by infection with Septata intestinalis. Gastroenterology 108:247-251

109. Wittner M (1999) Historic perspective on the microsporidia: expanding horizons. In: Wittner M, Weiss LM (eds) The microsporidia and microsporidiosis. A.M.S. Press, Washington DC, pp 1-6

110. Zhu X, Wittner M, Tanowitz HB, Kotler D, Cali A, Weiss LM (1993) Small subunit rRNA sequence of Enterocytozoon bieneusi and its potential diagnostic role with use of the polymerase chain reaction. J Infect Dis 168:1570-1575

Publisher's Note Springer Nature remains neutral with regard to jurisdictional claims in published maps and institutional affiliations. 